\title{
PREGNANCY WITH CARCINOMA CERVIX
}

Sunita Goyal' ${ }^{1}$, Arti Gupta Tuli² ${ }^{2}$ Aprajita Dsouza ${ }^{3}$, Tapasya Dhar Masih ${ }^{4}$

\section{HOW TO CITE THIS ARTICLE:}

Sunita Goyal, Arti Gupta Tuli, Aprajita Dsouza, Tapasya Dhar Masih. "Pregnancy with Carcinoma Cervix". Journal of Evolution of Medical and Dental Sciences 2014; Vol. 3, Issue 21, May 26; Page: 5685-5687,

DOI: $10.14260 /$ jemds/2014/2649

ABSTRACT: Invasive cervical cancer during pregnancy is rare, but is a dilemma for women and their physicians. Pregnancy provides a good opportunity to the obstetrician to screen the patient for cervical neoplasia. We report a case of pregnancy with carcinoma cervix. A 40 years old lady $\mathrm{G}_{5} \mathrm{P}_{3+1}$ presented in casualty at 38 weeks 2 days with bleeding per vaginum. On examination she was stage III b Carcinoma Cervix with term pregnancy. She underwent classical cesarean section followed by EBRT and brachytherapy. The main objective of this case report is to highlight the need of doing cervical screening routinely in pregnancy in a low resource setting also to decrease the burden of carcinoma cervix in society.

KEYWORDS: carcinoma, cervix, pregnancy.

INTRODUCTION: Cervical cancer is one of the most commonly diagnosed malignancies during pregnancy, with an estimated incidence of 0.8-1.5 cases per 10, 000 births ${ }^{1}$. Pregnancy provides a good opportunity to the obstetrician to screen the patient for cervical neoplasia. The diagnosis of cervical cancer is often delayed in pregnant women since many of these symptoms are similar to those associated with normal pregnancy. We report a case of pregnancy with carcinoma cervix.

CASE REPORT: A 40 year old lady married for 12 years $G_{5} P_{3+1}$ presented to emergency on $22^{\text {nd }}$ march 2013 at 38 weeks +2 days with bleeding per vaginum. She had minimal bleeding since morning. She had 3 previous normal vaginal deliveries and 1 spontaneous abortion and all the children were fine and healthy. Her last child birth was $1 \frac{1}{2}$ year back. She never had any complication in her previous pregnancies. There was no history of use of any family planning method. In this pregnancy there was no antenatal complication. There was no history of postcoital bleeding.

On examination she was pale; her pulse was 90/min, BP - 120/80 mm Hg. On abdominal examination uterus was term size, fetal heart rate was $140 / \mathrm{min}$ and regular with cephalic presentation. On per speculum examination an exophytic friable growth of $4 \mathrm{x} 4 \mathrm{~cm}$ seen on posterior lip of cervix. Growth was bleeding on touch. There was no local metastasis in the vagina. A punch biopsy was taken for histopathology.

On per vaginum examination anterior lip of cervix was smooth and there was a cauliflower friable growth felt at the posterior lip. Vertex was high up. Per rectal examination revealed involvement of parametrium upto lateral pelvic walls. Ultrasound showed hydronephrosis of right kidney. Diagnosis of term pregnancy with stage IIIb carcinoma of cervix was made. Her pre-operative investigations showed no abnormality except for low hemoglobin value $(7 \mathrm{gm} / \mathrm{dl})$ and she was transfused 2 units of blood pre operatively.

Her management was supervised by a team consisting of obstetrician \& gynecologist, oncologist, radiotherapist and histopathologist. We did a classical caesarean section to avoid the tumor. An alive female baby of 3792 gms was delivered, who cried immediately, APGAR score was 9. 


\section{CASE REPORT}

(normal). Intra operative findings showed that there was no bladder or uterosacral ligament involvement, but parametrium was found to be fibrosed. There was no ascites or palpable lymph nodes. The post-operative period was uneventful and the patient was discharged with her baby on $8^{\text {th }}$ post-operative day in good health.

Histopathology report showed a well differentiated squamous cell carcinoma. The patient was referred to radiotherapy unit where concurrent chemoradiation was planned. She received EBRT (external beam radiotherapy) 50.4 cGy in $28 \mathrm{~F}$ in 5.3 weeks with weekly Inj. Cisplatin $\left(40 \mathrm{mg} / \mathrm{m}^{2}\right)$ six doses. This was followed by ICRT (intracavitary radiotherapy). Follow up after one year revealed no recurrence.

DISCUSSION: Invasive cervical cancer during pregnancy is rare, but is a dilemma for women and their physicians. In most western countries with organized screening, the incidence of cervical cancer has dropped significantly in the last 20 years. ${ }^{2}$ There has also been a significant shift to earlier stage disease: for many women of childbearing age the diagnosis represents micro invasive cancer. This is associated with an excellent prognosis and can be managed without major impact on the current or future pregnancy. ${ }^{2}$ Clearly however the situation is different in the developing countries.

What is the impact of pregnancy on the stage at diagnosis? Does pregnancy adversely affect prognosis? What is the consequence of planned delay of treatment so the pregnancy can be continued to a viable gestation? What is the most appropriate treatment?

Stage is not affected adversely by pregnancy but the clinical stage is the most important prognostic factor for cervical cancer during pregnancy ${ }^{3}$. Treatment guidelines for pregnant patients with invasive cervical carcinoma are similar with those of non-pregnant patients. For patients with advanced disease, pregnancy impairs the prognosis ${ }^{4}$. In non-invasive cervical carcinoma treatment can be deferred until the postpartum period provided that careful colposcopic evaluation is performed in addition to cytology.

In early stage IA if patient wishes to continue pregnancy planned delay in therapy is safe provided regular pelvic examination with visual inspection, colposcopy, serial MRI for tumour size and spread is done. If patient does not want to continue pregnancy then active management is preferable

Stage IA2, IB, IIA classical cesarean section (if viable baby)/ Hysterotomy (if non-viable baby) followed by Radical hysterectomy and pelvic/ para-aortic lymphadenectomy. Complications are increased operative time, increased blood loss, and fistulae formation. Advantage is carrying out surgery in one sitting. ${ }^{5}$

In locally advanced carcinoma neoadjuvant chemotherapy (NACT) with paclitaxel and cisplatin can be considered in patient after 13 weeks gestation who do not wish to terminate pregnancy. ${ }^{3}$

Stage IIB to IV - if the fetus is viable, classical caesarean birth with EBRT postoperatively followed by brachytherapy. A delay of several weeks is required for involution of uterus to occur prior to brachytherapy5. If pregnancy is prior to fetal viability the whole pelvic irradiation is initiated and patient usually undergoes a spontaneous abortion at 2-3 weeks after initiation of therapy.

The KEY to further limitation of mortality and morbidity from carcinoma cervix is cervical screening. 


\section{CASE REPORT}

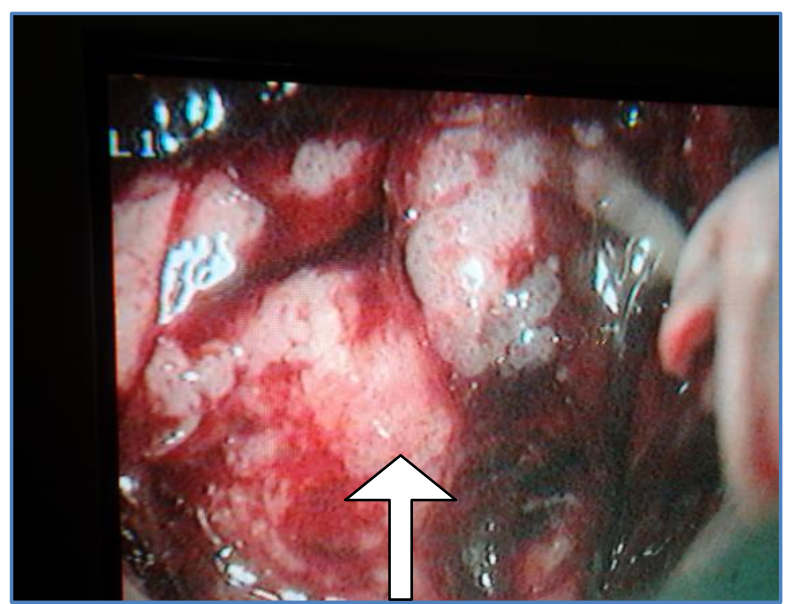

\section{CAULIFLOWER GROWTH ON POSTERIOR LIP OF CERVIX}

\section{BIBLIOGRAPHY:}

1. Smith LH, Dalrymple JL, Leiserowitz GS et al. Obstetrical deliveries associated with maternal malignancy in California, 1992 through 1997. Am J Obstet Gynecol 2001; 184: 1504- 22.

2. Elhassan M Elhassan, Omer A Mirghani, Ahmed A Mohamadani et al. Cervical carcinoma in pregnancy. Gynaecol Perinatol 2009; 18(2):93-95.

3. Bader AA, Petru E, Winter R. Long term follow-up after neoadjuvant chemotherapy for high-risk cervical cancer during pregnancy. Gynecol Oncol 2007;105 : 269-272.

4. Hacker NF, Berek JS, Lagasse LD et al. Carcinoma of cervix associated with pregnancy. Obstet Gynecol 1982; 59:735-746.

5. Saha Sudip Kumar, Mandal Tanmay, Saha Arindam. Pregnancy with carcinoma cervix. The Journal of Obstetrics and Gynaecology of India (December 2012) 62(S1):S38-39.

\section{AUTHORS:}

1. Sunita Goyal

2. Arti Gupta Tuli

3. Aprajita Dsouza

4. Tapasya Dhar Masih

\section{PARTICULARS OF CONTRIBUTORS:}

1. Professor and HOD, Department of Obstetrics and Gynaecology, Christian Medical College and Hospital, Ludhiana.

2. Assistant Professor, Department of Obstetrics and Gynaecology, Christian Medical College and Hospital, Ludhiana.

3. Associate Professor, Department of Obstetrics and Gynaecology, Christian Medical College and Hospital, Ludhiana.
4. Professor, Department of Obstetrics and Gynaecology, Christian Medical College and Hospital, Ludhiana.

\section{NAME ADDRESS EMAIL ID OF THE CORRESPONDING AUTHOR:}

Dr. Sunita Goyal,

Department of Obstetrics and Gynaecology,

Christian Medical College and Hospital,

Ludhiana.

Email: goyalsunita11@gmail.com

Date of Submission: 08/05/2014.

Date of Peer Review: 09/05/2014.

Date of Acceptance: 17/05/2014.

Date of Publishing: 21/05/2014. 